\title{
Uso Das Redes Sociais Por Órgãos Públicos No Brasil E Possibilidades De Contribuição Do Monitoramento Para Gestão
}

\section{Use Of Social Media By Public Agencies In Brazil And Contributions Of Monitoring To Administration}

\author{
Marília Barreto de Santana ${ }^{1}$, Cristiane Gabriela Boesing de Souza ${ }^{2}$
}

\author{
${ }^{1}$ Faculdade Integrada de Pernambuco, FACIPE, Brasil \\ ${ }^{2}$ Universidade Federal do Rio Grande do Sul, UFRGS, Brasil \\ Correspondência: Marília Barreto de Santana. Endereço: Av. Caxangá, 4477, Várzea, Recife, PE, 50740-000 E- \\ mail: mariliabsantana@gmail.com
}

Recebido: 28 de novembro de 2017 Aceito: 15 de dezembro de 2017 Publicado: 31 de dezembro de 2017

DOI: http://dx.doi.org/10.21714/1679-18272017v15Ed.p99-107

\begin{abstract}
Resumo
A administração pública atualiza-se constantemente em relação às mudanças no mundo moderno e tecnológico. A fim de alcançar uma gestão efetiva, e considerando a alta intensidade da presença das redes sociais no cotidiano do brasileiro, o monitoramento de mídias sociais tem sido uma das ferramentas estratégicas por ela utilizada. Sendo assim, o presente artigo tem como objetivo compreender as contribuições que o monitoramento de mídias e o uso de redes sociais têm proporcionado aos órgãos públicos no Brasil. A pesquisa nesta temática justifica-se por permitir esclarecer aspectos dos benefícios do monitoramento de mídias, que vêm sendo absorvidos por algumas organizações recentemente, e a ênfase em órgãos públicos, por poder demonstrar as decorrentes melhorias na relação entre cidadão e administrador. Visando este objetivo, foi realizada uma pesquisa bibliográfica nos conceitos relacionados ao assunto e em estudos de casos, que após serem repensados para o ambiente público, serviram como referência. Ao fim da pesquisa, são apresentadas as evidências de que o monitoramento pode ajudar a gestão pública em inúmeros fatores, mas principalmente a entender melhor os sentimentos da sociedade, suas reivindicações e necessidades.
\end{abstract}

Palavras-chave: Mídias sociais; Monitoramento; Administração Pública.

\begin{abstract}
Public administration is constantly updated in relation to changes in the modern and technological world. In order to achieve an effective management, and considering the high intensity of the presence of social networks in Brazilian daily life, the monitoring of social media has been one of the strategic tools used by it. Thus, the present article aims to understand the contributions that media monitoring and the use of social networks have provided to public agencies in Brazil. The research in this area is justified by the fact that it clarifies features of the benefits of media monitoring, which have been absorbed by some organizations recently, and the emphasis on public agencies, to be able to demonstrate the resulting improvements in the relationship between citizen and administrator. Aiming at this objective, a bibliographical research was carried out on the concepts related to the subject and on case studies, which, after being rethought for the public environment, served as reference. At the end of the research, the evidences that monitoring can help public administration on numerous factors are presented, but chiefly to allow a better understanding of society's feelings, demands and needs.
\end{abstract}

Keywords: Social media; Monitoring; Public Administration.

Esta obra está licenciada sob uma Licença Creative Commons Attribution 3.0.

\section{Introdução}

Diversas transformações ocorreram tanto no formato da administração pública quanto nas configurações da comunicação desde que surgiram. A primeira, oriunda da Revolução Francesa, alterou sua relação com a sociedade, visando atualizar sua eficiência para que colaborasse com o desenvolvimento público. A segunda, por 
sua vez, que teve seu surgimento junto aos homens das cavernas, em formato verbal, não-verbal e corporal, aprimorou suas técnicas, ferramentas e possibilidades.

As mudanças que se deram ao adentrar a década de 90, estão diretamente relacionadas à revolução tecnológica e à explosão informacional. $\mathrm{O}$ acesso à informação se multiplicou, ao expandir o alcance da internet, e ao popularizar mais as mídias que dão acesso às respectivas redes.

Sendo assim, o presente artigo relacionará três eixos: administração pública, comunicação e informação, e tecnologia. A comunicação é o elemento de enlace entre os outros eixos, considerando que, é com o objetivo de informar e comunicar, que Administração Pública trocou suas estratégias e vem interagindo a cada dia mais com a sociedade por meio da tecnologia. Dentro do universo da comunicação digital, o foco do artigo é dado às mídias e redes sociais digitais.

As mídias digitais e as redes sociais estão intensamente presentes no cotidiano da sociedade. Segundo notícia publicada em 2016 na Forbes, o Brasil é o país que mais utiliza as redes sociais na América Latina, somando 93,2 milhões de usuários. Em 2017, de acordo com o estudo Digital in 2017 Global Overview, já existem 122 milhões de usuários ativos nas redes. Por esse motivo, tanto instituições públicas como privadas deram início à utilização dessas mídias como ferramentas estratégicas no desenvolvimento de suas atividades.

Sendo assim, este trabalho tem como objetivo analisar quais as contribuições do monitoramento das mídias sociais e uso de redes sociais por órgãos públicos no Brasil, visando destacar quais as mudanças decorrentes da utilização das redes no processo comunicacional entre governo e sociedade, e como o monitoramento pode colaborar com a gestão desses órgãos.

\section{Uso das redes sociais por órgãos públicos no Brasil e possibilidades de contribuição do monitoramento de mídias digitais para gestão}

Para que seja possível identificar as contribuições do uso das redes sociais, e de monitoramento de mídias digitais nos órgãos públicos do Brasil, é necessário realizar um percurso de compreensão conceitual relacionado ao tema. Portanto, será discorrido agora sobre a comunicação organizacional digital, a comunicação digital nos órgãos públicos, e por fim, sobre o monitoramento de mídias digitais.

\subsection{Comunicação organizacional digital}

Em Mainieri de Oliveira (2011, p.538), temos que "a comunicação é o ponto de partida da comunicação organizacional. Portanto, enquanto um subcampo da comunicação, a comunicação organizacional refletirá o impacto das tecnologias no seu pensar e fazer".

O avanço tecnológico, especialmente relacionado às tecnologias digitais da informação e comunicação, ocorridas a partir do século XX, acarretou diversas mudanças na sociedade atual e exigiu que a comunicação organizacional se reconfigurasse diante das possibilidades da era digital. Vale salientar que embora normalmente as tecnologias de informação (TI) e comunicação (TC) sejam apresentadas de forma homogênea, é importante diferenciar seus impactos nas empresas: os investimentos em TC influenciarão diretamente na autonomia dos funcionários e relacionamentos, em TI, por sua vez, reduzirão os custos para aquisição de informações, fornecendo dados e métricas a fim de facilitar a tomada de decisão (BLOOM, GARICANO, SADUN, e VAN RENEEN, 2010).

A comunicação corporativa no meio digital não se restringe à mera existência de um sítio na internet ou ao uso do correio eletrônico, ela engloba o planejamento de estratégias mais abrangentes para o uso da web, a fim de estabelecer os canais de comunicação e as respectivas ferramentas para que a empresa fale da melhor maneira com seus diferentes públicos, tanto com o intuito de iniciar o relacionamento com seus stakeholders, quanto de fortalecer os laços e o diálogo com eles (RIBEIRO, 2014).

Inicialmente, essas mudanças poderiam ser interpretadas como uma chance de enfraquecimento do processo de comunicação tradicional das organizações, antes mediado pela imprensa, "em um segundo momento, porém, não há mais só o ambiente tradicional; estamos presenciando a ambiência digital em seu processo contínuo de desenvolvimento como mais um espaço estratégico de comunicação das organizações" (BARICHELLO, LASTA, 2010, p. 4)

As estratégias de comunicação digital devem se direcionar para o planejamento, elaboração de objetivos e metas, compreensão dos públicos, monitoramento e avaliação de ações, que possibilitem perceber se os objetivos gerais determinados pela organização estão sendo alcançados.

Tendo em vista que é possível a convivência entre diferentes estratégias de presença digital, Corrêa (2009) 
propõe "um modelo adaptável a diferentes ambientes e contextos organizacionais e construído em dois estágios de desenvolvimento: o posicionamento estratégico e a constituição dos espaços-informação" (CORRÊA, 2009, p. 328), com o objetivo de auxiliar as organizações que pretendem planejar a comunicação organizacional digital, incorporando aspectos da estratégia empresarial geral estabelecida pela organização. Segundo o modelo, a presença no ciberespaço deve estar em harmonia com as seguintes instâncias do meio corporativo: i) Cultura e imagem organizacionais; ii) Propósitos e intenções pretendidas com as ações de comunicação digital; iii) Stakeholders com os quais conversa; iv) Mensagens que reflitam a organização para todos e cada um de seus públicos.

Baseado nesse pressuposto, ainda segundo a autora, o primeiro passo é compreender a relação da cultura empresarial com a inovação e tecnologia, depois, conhecer os públicos estratégicos para definir os canais ou veículos de comunicação. Após essa etapa é possível definir os propósitos e as intenções das ações de comunicação digital, para então dar início a estruturação do conteúdo das mensagens formatadas de acordo com os públicos aos quais se destinam.

Em meio as formas de comunicação digital, o uso das redes sociais por organizações é cada vez mais frequente. Segundo o estudo Social Media Trends 2017, elaborado pela empresa Rock Content, 92,1\% das empresas estão presentes em alguma Rede Social, especialmente com o objetivo de ganhar mais visibilidade para sua marca e conseguir atrair o público ideal e, dessa forma, conquistar novos clientes. Em relação à eficácia dessas empresas nas Redes Sociais, cerca de $50 \%$ se consideram muito ou moderadamente eficazes. Sobre os resultados obtidos, $71,9 \%$ acreditam que são muito ou moderadamente satisfatórios (EXAME, 2017).

Vê-se, hoje, que as formas como as organizações se relacionam com seus públicos geram impactos na própria busca pelo posicionamento e sustentabilidade organizacional, e o uso de ferramentas e redes sociais digitais possibilitam estreitar relacionamentos e propõem uma nova forma desse posicionamento estratégico. O fazer comunicacional, portanto, deve permitir experiências que podem, em determinados momentos, ultrapassar aspectos meramente comerciais e criar uma cultura da participação, especialmente através das mídias e redes sociais (FALCO, 2017).

\subsubsection{Comunicação digital em órgãos públicos}

Brandão (2009) afirma que a comunicação governamental no Brasil possui uma natureza essencialmente publicitária, ou seja, o maior objetivo é divulgar ações e utilizar a propaganda para veiculação na mídia, especialmente através das assessorias de comunicação, que na esfera do governo, atuam desde a década de 70 .

No entanto, com a popularização das tecnologias de informação e comunicação, percebe-se que é inapropriado o uso da comunicação governamental apenas dessa forma, tendo em vista que como vê-se em Nascimento (2013): "O acesso às informações de utilidade pública é de suma importância, mas deve ser associado à criação de espaços de interlocução e à prática da transparência pública".

Com a internet, na esfera da comunicação pública, é possível "proporcionar um meio de interação através do qual o público e os políticos podem trocar informações, consultar e debater, de maneira direta, contextualizada, rápida e sem obstáculos democráticos" (MAIA, 2002). Complementando essa ideia, temos em Duarte (2007) que "a comunicação e as novas tecnologias da informação têm influenciado decisivamente o processo de transformação da sociedade brasileira, em especial o estabelecimento de uma nova cultura política, que propugne pela participação política baseada na conscientização e não simplesmente no dever cívico do voto".

A utilização das mídias sociais é uma forma de dilatar os canais de comunicação utilizados pelos órgãos públicos, pois, para o Estado, representa uma plataforma de interação com a sociedade, tanto para divulgação de informações públicas e controle social dos atos administrativos, quanto para o monitoramento do conteúdo resultante dessa interação (SANTOS, 2016).

Sobre o uso das redes sociais como recurso da comunicação digital, em 2013, o estudo Mapa da Comunicação Brasileira, do Instituto FSB Pesquisa, já apontava as mídias sociais como a segunda atividade mais citada na área de comunicação do setor público. Percebeu-se ainda que com o surgimento de novos líderes de opinião nas redes sociais, $94 \%$ dos gestores do setor público acreditavam ser preciso traçar novas estratégias de comunicação para se adequar a essa realidade. $56 \%$ desses gerentes informaram que precisaram alterar o desenho e a conformação da equipe de comunicação.

Ainda de acordo com o estudo, viu-se que o setor público tem características próprias que sua comunicação deve atender, especialmente pelas peculiaridades da cultura organizacional: "A valorização da conduta ética, a preocupação com a reputação e a consciência dos deveres de servir ao cidadão são valores que norteiam os gestores de órgãos públicos e explicam as diferenças mais evidentes reveladas na pesquisa". 
Dados da pesquisa TIC - Governo Eletrônico 2015, lançado pelo Comitê Gestor da Internet no Brasil, por sua vez, apontam que há disparidades por região do País no que tange a presença na Internet. O índice de prefeituras que têm website é praticamente universalizado nas regiões Sul (99\%), Centro-Oeste (98\%) e Sudeste (92\%), enquanto a proporção é menor na região Norte (78\%) e Nordeste (76\%). Quanto ao indicador de presença das prefeituras nas redes sociais, os resultados são menos discrepantes: A existência de perfil ou conta própria em redes sociais foi mencionada por $67 \%$ das prefeituras do Norte, $66 \%$ dos municípios do Nordeste, Sul e CentroOeste, e 64\% do Sudeste. Ao se comparar as esferas governamentais, o Executivo (91\%) obteve o menor percentual de presença por website. A pesquisa mostra que $92 \%$ dos órgãos públicos federais e $74 \%$ dos estaduais possuem perfil ou conta própria em redes sociais. No Judiciário, 99\% dos órgãos possuem website e 94\% perfil em alguma rede social.

Outros dados do estudo mostram que sobre a atualização dos perfis, $84 \%$ das prefeituras fazem publicações diárias ou pelo menos uma vez por semana. Entre as principais atividades vê-se: postar notícias sobre a prefeitura (95\%), divulgar serviços ou campanhas (90\%), e responder a dúvidas e comentários dos cidadãos (77\%). No que se refere aos órgãos públicos federais e estaduais, 86\% atualizam suas redes todos os dias ou ao menos uma vez por semana. Sobre as atividades desempenhadas, tem-se: postar notícias sobre os órgãos públicos (93\%), divulgar serviços ou campanhas (90\%), e responder a dúvidas e comentários dos cidadãos $(82 \%)$.

\subsection{Monitoramento de Mídias Sociais Digitais}

Para Oliveira (2015), o monitoramento digital é:

Uma ferramenta de pesquisa que se baseia nas conversações publicadas nas mídias sociais para geração de insights e oportunidades de negócio. Trata-se da coleta, classificação e análise de menções públicas em sites de mídias sociais em relação a palavras-chave previamente definidas.

Ciribeli (2011) afirma que apenas a boa utilização das redes sociais é insuficiente, tornando-se necessário a elaboração e utilização de ações e estratégias de monitoramento e, para tal, existem programas que com algumas técnicas facilitam o acompanhamento e a intervenção imediata, caso necessário.

O monitoramento de mídias sociais proporcionou a abertura de novas possibilidades de comunicação, e uma consequente aproximação, entre usuário e instituição, assim como acorda Antunes (2014, p.10) ao dizer que "ao capturar dados que frequentemente escapam às fontes de informação oficiais, abriram-se novas perspectivas para o monitoramento, principalmente, por meio das mídias sociais".

Na Figura 1, Monteiro e Azarite (2012, p. 82) apresentam um modelo cíclico das etapas ocorrentes durante o processo de monitoramento:

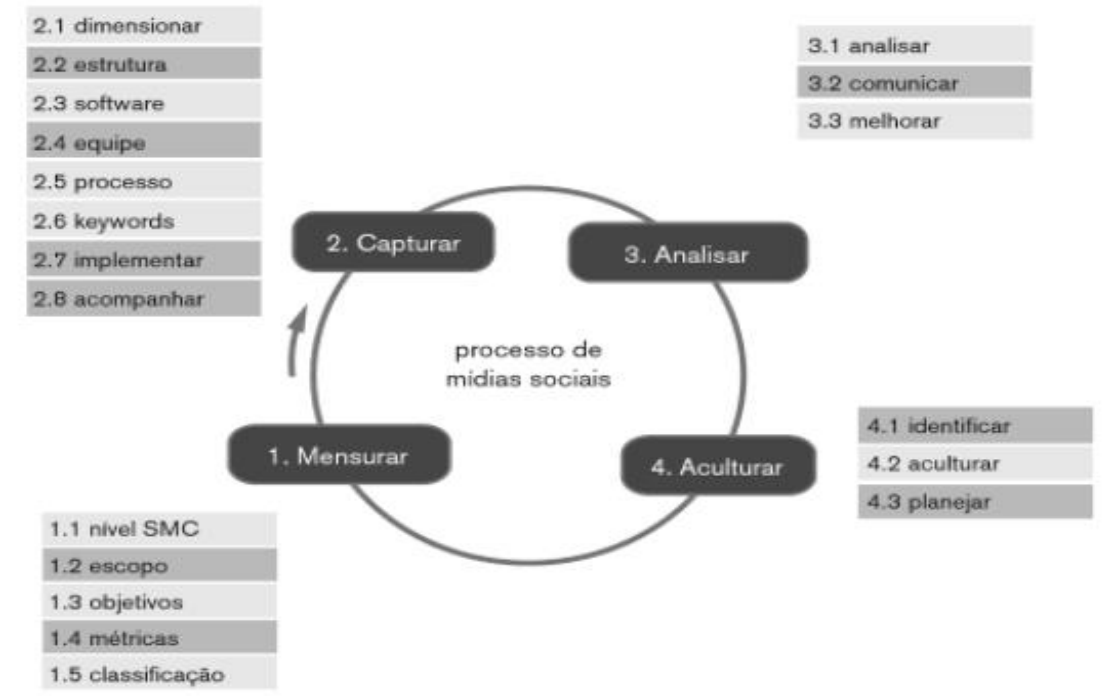

Figura 1: Modelo SMC (Ciclo de mídias sociais) de monitoramento e métrica em mídias sociais.

Fonte: Monteiro; Azarite (2012, p. 82).

A imagem supracitada demonstra que o monitoramento de mídias sociais é um processo infinito, que envolve as 
seguintes etapas: mensuração, captura e análise, e aculturação. À medida que as fases vão sendo concluídas, novas informações são publicadas, trazendo novos materiais para análise. Além disso, as constantes mudanças no cotidiano transformam as opiniões, tornando as informações obsoletas em um curto prazo de tempo.

Assim como dito anteriormente, o benefício da ampliação do acesso às mídias é que houve uma aproximação pessoa-pessoa e pessoa-organização, revelando tipos informacionais antigamente não disponíveis apenas nos meios de comunicação formais. A Figura 2, proposta por Monteiro e Azarite (2012) demonstra, por meio de definições e exemplos, os tipos de informação que podem ser recuperadas nas mídias sociais.

\begin{tabular}{|c|c|c|}
\hline & definiçāo & exemplo \\
\hline 1. opiniẫo & $\begin{array}{l}\text { julgamento de valor / opiniẫo a } \\
\text { respeito sobre algo }\end{array}$ & $\begin{array}{l}\text { sentimento positivo, neutro, negativo, } \\
\text { gostei, nấo gostei, recomendaçăo ... }\end{array}$ \\
\hline 2. relacional & $\begin{array}{c}\text { sua capacidade de ser visto e } \\
\text { poder de influencia }\end{array}$ & $\begin{array}{l}\text { compartilhamentos de conteúdos e } \\
\text { informaçōes ... }\end{array}$ \\
\hline 3. públlico & $\begin{array}{l}\text { perfil de quem está interagindo / } \\
\text { mencionando }\end{array}$ & $\begin{array}{l}\text { influenciador , consumidor, } \\
\text { público ... }\end{array}$ \\
\hline 4. demográfico & identidade dos individuos & sexo, idade, localização ... \\
\hline 5. audiêncla & alcance da mençäo identificada & $\begin{array}{l}\text { seguidores, impressōes de anúncio, } \\
\text { cliques, tempo de acesso ... }\end{array}$ \\
\hline 6. participaçäo & $\begin{array}{l}\text { qual parcela da audiéncia interagiu } \\
\text { com o conteúdo monitorado }\end{array}$ & $\begin{array}{c}\text { comentários, mensagens, respostas, } \\
\text { compartilhamentos ... }\end{array}$ \\
\hline 7. transacional & relacionados a compra e venda & $\begin{array}{l}\text { Produtos comprados, taxa de } \\
\text { recompra ... }\end{array}$ \\
\hline 8. navegaçâ๋ & $\begin{array}{l}\text { trajetórias e usos de } \\
\text { acessos a sites }\end{array}$ & $\begin{array}{c}\text { fonte de acessos, páginas visitadas, } \\
\text { taxa de rejeiçầo ... }\end{array}$ \\
\hline
\end{tabular}

Figura 2: Tipos de dados de mídias sociais.

Fonte: Monteiro; Azarite (2012, p. 96).

Os variados tipos de informações que podem ser recuperados após devido tratamento são utilizados para apresentar alguns indicadores. Barger (2013) informa que variadas ferramentas de monitoramento de mídias permitem identificar as menções à sua marca, atestando o volume e o alcance, a fidedignidade, a responsividade, e a influência do conteúdo publicado, e dessa forma, verificar se o seu objetivo de compartilhamento de informação foi atendido.

Sendo assim, a seção a seguir, apresentará as contribuições que o monitoramento de mídias sociais e o uso de redes sociais podem acarretar aos órgãos públicos.

\subsection{Contribuições do monitoramento de redes sociais para gestão de órgãos públicos}

No governo, o monitoramento de mídias sociais pode subsidiar a elaboração de políticas públicas, pois permite uma avaliação rápida e de baixo custo das opiniões, atitudes e sentimentos das pessoas e permite a identificação de diferenças entre os diferentes grupos de cidadãos e também de líderes de opinião digitais (geralmente associados a partes interessadas importantes). Além disso, ajuda a entender a evolução temporal da atitude pública - seu sentimento - contra questões políticas / tópicos de interesse, e a identificar novas questões / tópicos relevantes emergentes e tendências na sociedade (ANDROUTSOPOULOU, CHARALABIDIS E LOUKIS, 2015).

Por meio da análise do material proveniente das mídias sociais, os gestores públicos têm a possibilidade de instrumentalizar os interesses dos cidadãos para o desenvolvimento de políticas públicas mais efetivas e que supram ou até mesmo superem as necessidades da sociedade. Para Rocha (2014), esses interesses devem estar em primeiro lugar, ao se realizar o monitoramento de mídias digitais, e não relacionado a campanhas eleitorais. A autora acredita que o setor público deve utilizar o monitoramento com o objetivo semelhante ao das empresas privadas: "gerar informação estratégica para os gestores criando padrões para adquirir, criar, distribuir e usar as informações disponíveis nos ambientes interno e externo dessas organizações" (ROCHA, 2014, p. 18). O Quadro 1 sintetiza as contribuições do monitoramento de mídias sociais, e as mesmas para gestão pública, e em seguida serão dados exemplos do uso de mídias sociais na esfera pública no Brasil e oportunidades criadas pelo monitoramento. 
Quadro 1:Moitoramento de mídias sociais.

\begin{tabular}{|l|c|}
\hline $\begin{array}{l}\text { Contribuiçães do uso do monitoramento de } \\
\text { mídias sociais }\end{array}$ & $\begin{array}{c}\text { Contribuição do uso do monitoramento de } \\
\text { mídias sociais para a gestão pública }\end{array}$ \\
\hline $\begin{array}{l}\text { Avaliação da imagem da organização e } \\
\text { sentimento do público em relação a ela }\end{array}$ & $\mathrm{X}$ \\
\hline Suporte ao desenvolvimento de políticas públicas \\
\hline $\begin{array}{l}\text { Verificação da satisfação do público com os } \\
\text { serviços prestados }\end{array}$ & $\mathrm{X}$ \\
\hline $\begin{array}{l}\text { Maior velocidade na identificação de dúvidas do } \\
\text { público }\end{array}$ & $\mathrm{X}$ \\
\hline $\begin{array}{l}\text { Mensuração do engajamento, sentimento e redes } \\
\text { mais utilizadas pelos seguidores }\end{array}$ & $\mathrm{X}$ \\
\hline Identificação de influenciadores de opinião & $\mathrm{X}$ \\
\hline Suporte à prevenção e/ou gerenciamento de crises & $\mathrm{X}$ \\
\hline $\begin{array}{l}\text { Maior quantidade de informação qualificada para } \\
\text { tomada de decisão }\end{array}$ & $\begin{array}{c}\text { Não se aplica (consideramos que órgãos públicos } \\
\text { não são concorrentes). }\end{array}$ \\
\hline Comparação com a concorrência & \\
\hline
\end{tabular}

Fonte: As autoras (2017)

A presença digital da Prefeitura de Curitiba é um dos maiores casos de sucesso do uso de mídias sociais no Brasil. Segundo o estudo de Santos e Harmata (2013), a experiência pioneira do órgão mostrou como "o equilíbrio entre uso do humor e uma linguagem adequada ao meio com informações e serviço público podem provocar aproximação entre um órgão público e sua população", foram percebidos resultados práticos nos canais de atendimento e maior velocidade no esclarecimento de dúvidas do cidadão. Uma experiência positiva do uso das redes se deu pela abertura para contribuições para Lei Orçamentária Anual. Segundo dados do órgão, foram 4.218 contribuições que chegaram por meio da internet, em contrapartida, apenas 1.267 vieram por outros meios, como urnas e central 156. De acordo com os autores, esse exemplo mostra "a importância do diálogo aberto nas redes sociais para discutir os rumos do município".

Baccin e Cruz (2015) investigaram o uso das mídias sociais pela Polícia Militar de Santa Catarina como instrumento de contato com a comunidade para o incremento da filosofia da Polícia Comunitária, e como consequência, a melhoria da segurança pública. Os autores defendem a presença digital do órgão e maior interação com o público, pois, através da análise do conteúdo publicado pelos cidadãos, se faz possível "identificar, priorizar e atuar sobre causas de crime, violência e desordem". Com o monitoramento, por exemplo, há como reunir informações sobre ocorrências em determinada localidade, e assim traçar estratégias de forma mais assertiva. De maneira geral, segundo eles, "as redes sociais se apresentam como um importante aliado, de baixo custo operacional, para engajar a comunidade na busca de soluções criativas para os problemas locais de segurança".

Santos (2016) analisou a página do Senado Federal no Facebook. Além de fazer inferências sobre a presença digital do Senado como um todo, ele analisou as respostas ao post "E agora, quem poderá me defender?", de agosto de 2015, que se tratava da efetividade dos direitos civis, e pressupunha o envolvimento de diversos órgãos estatais. $\mathrm{O}$ autor concluiu que os gestores da página ainda não utilizam todo o potencial oferecido pelo monitoramento dos comentários do público, e verificou uma maior necessidade de interagir com os fãs e alinhar as decisões coletivas à vontade popular. Santos percebeu ainda a má reputação do Senado Federal e outros órgãos relacionados ao tema do post, e defendeu que através das análises provenientes do monitoramento, as mídias sociais sejam utilizadas para contribuir com a melhoria da imagem do Estado perante o público.

O site Juntos pela Água e a empresa Seekr desenvolveram um estudo que monitorou a percepção dos internautas sobre o saneamento básico em São Paulo, nas páginas abertas no Facebook durante o período de candidatura e pós-eleição.

Sobre o monitoramento das redes sociais do prefeito eleito de São Paulo João Doria (PSDB), por exemplo, viu- 
se que o tema ficou em sexto lugar no ranking de assuntos abordados, com uma presença tímida nas postagens do político, houve apenas um post próprio e quatro comentários sobre o assunto, enquanto que os internautas fizeram mais de 570 menções sobre saneamento. O estudo mostrou que embora de acordo com o SNIS (Sistema Nacional de Informações sobre Saneamento), mais de 35 milhões de brasileiros ainda não tenha acesso aos serviços de água potável, 100 milhões não tenha serviço de coleta de esgoto e só $40 \%$ do esgoto produzido no país é tratado, políticas de saneamento básico recebem baixa atenção pelos políticos durante a campanha eleitoral (SEEKR, 2017). Esses dados podem ser utilizados pela gestão como subsídio informacional para tomada de decisões referentes ao tema, a fim de atender as reivindicações populares.

\section{Conclusão}

Segundo o estudo Digital in 2017 Global Overview, realizado We Are Social e Hootsuite, no Brasil há 139 milhões de usuários de Internet, dos quais 122 milhões também são usuários ativos das redes sociais. Diante desse cenário, conclui-se que a presença digital de instituições privadas e públicas nesse meio se tornou uma obrigação para quem quer se comunicar, estreitar e fortalecer laços com a sua audiência.

Percebe-se que o ambiente digital provocou mudanças na forma do setor público se comunicar, visto que a comunicação não pode mais ser unicamente transmissiva e unilateral, é preciso gerar um espaço para interação e fortalecimento da democracia.

No artigo apresentado, viu-se que, na esfera pública, estudos apontam que $86 \%$ de órgãos federais e estaduais e $84 \%$ das prefeituras fazem publicações nos seus perfis ao menos uma vez na semana. As mídias sociais digitais se apresentam como uma plataforma de interação com a sociedade, na qual os órgãos podem divulgar informações públicas e acompanhar a percepção dos internautas sobre suas ações e serviços. Além de identificar a reputação da imagem do órgão perante a sociedade, através do monitoramento do conteúdo publicado nas redes sociais, é possível gerar insights e alinhar as estratégias governamentais com os anseios e expectativas dos cidadãos. A partir dessas informações, pode-se dizer que o objetivo de analisar quais são as contribuições do monitoramento das mídias sociais e do uso de redes sociais por órgãos públicos no Brasil foi atingido.

O monitoramento contribui na identificação dos usuários das redes que mais defendem ou criticam os órgãos, no mapeamento dos setores da gestão que estão mais carentes de atenção, priorização dos serviços e ações de acordo com as localidades, definição de despesas e receitas pela administração com base nas reivindicações do povo, aumento da velocidade no esclarecimento de dúvidas dos cidadãos, dentre outras possibilidades. Em suma, para os gestores públicos, o monitoramento de mídias sociais é uma ferramenta que, se bem utilizada, oferece um subsídio informacional de grande valor para o desenvolvimento de políticas baseadas nos interesses da população.

Por fim, vale lembrar que este estudo poderá ser utilizado para esclarecer aos gestores que ainda estão em dúvida, como o monitoramento pode ajudar sua instituição, além de servir como base teórica para à futuras análises referentes à eficácia do monitoramento de mídias em outros ambientes, não se restringindo à esfera pública.

\section{Referências}

ANDROUTSOPOULOU, A.; CHARALABIDIS, Y.; LOUKIS, E. N. Using Social Media Monitoring for Public Policy Making - An Evaluation. MCIS 2015 Proceedings. 8. Disponível em: http://aisel.aisnet.org/mcis2015/8 . Acesso em: 05 set. 2017.

ANTUNES, M.; et. al. Monitoramento de informação em mídias sociais: o e-Monitor Dengue. TransInformação, Campinas, 26(1):9-18, jan./abr., 2014. Disponível em: <http://periodicos.puccampinas.edu.br/seer/index.php/transinfo/article/view/2234/1806> Acesso em: 10 jul. 2017.

BACCIN, L. R. S; CRUZ, T. M. F. Uma reflexão sobre a utilização das redes sociais como forma de auxílio na atuação da polícia comunitária. Revista Ordem Pública e Defesa Social, p. 13, 34, 01 Dez. 2015 . Disponível em: <https://rop.emnuvens.com.br/rop/article/view/131>. Acesso em: 04 ago. 2017.

BARGER, C. O estrategista em mídias sociais: desenvolva um programa bem-sucedido trabalhando de dentro para fora em sua empresa. São Paulo: DVS Editora, 2013.

BARICHELLO, E. M. da R. LASTA, E. Comunicação organizacional digital a cauda longa da informação gerada pelo blog corporativo Fatos \& Dados da Petrobras. Lumina: Revista do Programa de Pós-graduação em Comunicação da Universidade Federal de Juiz de Fora / UFJF.n. 2, v. 4, dez. 2010. Disponível em: $<\mathrm{http}: / /$ professor.ufrgs.br/elisangela- 
lasta/files/comunicacao_organizacional_na_midia_digital_a_cauda_longa_da_informacao_gerada_apos_o_lanca mento_do_blog_> Acesso em: 04 ago. $201 \overline{7}$.

BLOOM, N.; GARICANO, L.; SADUN, R.; VAN REENEN, J. The distinct effects of Information Technology and Communication Technology on firm organization. Harvard Business School. Working Paper 11-023. 2010. Disponível em: http://www.people.hbs.edu/rsadun/Distinct_Effects_11-023.pdf. Acesso em: 06 set. 2017.

BRANDÃO, E. P. Conceito de Comunicação Pública. In: DUARTE, J. Comunicação Pública: estado, mercado, sociedade e interesse público. São Paulo: Atlas, 2009. 2. ed.

BRASIL é o maior usuário de redes sociais da América Latina. Revista Forbes. Disponível em: $<$ http://www.forbes.com.br/fotos/2016/06/brasil-e-o-maior-usuario-de-redes-sociais-da-america-latina/ $>$. Acesso em: 15 jun. 2017

CIRIBELI, J. P.; PAIVA, V. H. P. Redes e mídias sociais na internet: realidades e perspectivas de um mundo conectado. Mediação, Belo Horizonte, v. 13, n. 12, jan./jun. de 2011. Disponível em: <http://www.fumec.br/revistas/mediacao/article/view/509/504> Acesso em: 10 jul. 2017

COMITE GESTOR DA INTERNET NO BRASIL. TIC - Governo Eletrônico 2015. Disponível em: $<$ http://cetic.br/pesquisa/governo-eletronico/indicadores>. Acesso em: 04 ago. 2017.

CORRÊA, E. S. Comunicação Digital e novas mídias institucionais. In: KUNSCH, Margarida M. Krohling .Comunicação Organizacional: Histórico, fundamentos e processos -Volume 1.São Paulo: Saraiva, 2009. p. $317-335$.

DINO VISIBILIDADE ONLINE. Pesquisa inédita mostra as principais tendências no uso de Redes Sociais por empresas brasileiras. Comunicação Corporativa. Exame.com. Janeiro, 2017. Disponível em: $<$ http://exame.abril.com.br/negocios/dino/pesquisa-inedita-mostra-as-principais-tendencias-no-uso-de-redessociais-por-empresas-brasileiras-shtml/>. Acesso em: 04 ago. 2017.

DUARTE, J. Comunicação Pública. Disponível em: $<$ http://www.jforni.jor.br/forni/files/ComP\%C3\%BAblicaJDuartevf.pdf>. Acesso em: 04 ago. 2017.

FALCO, R. Comunicação organizacional digital: O papel das mídias e redes sociais. In: Congresso LatinoAmericano de Administração e Negócios. Paraná, 2017. Disponível em: $<$ http://conlaan.com.br/artigo_nome/276_08052017_94.pdf>. Acesso em: 04 ago. 2017.

FSB PESQUISA. Mapa da Comunicação Brasileira. Brasília, 3ed., 2013. Disponível em: $<$ http://www.institutofsbpesquisa.com.br/pdf/Mapa-da-comunicacao-2013.pdf>. Acesso em: 04 ago. 2017.

MAIA, R. C. M. Redes Cívicas e Internet. Do ambiente informativo denso às condições de deliberação pública. p. 46-72. Internet e Política- Teoria e Prática da Democracia Eletrônica. Belo Horizonte: Editora UFMG, 2002.

MAIA, A. K. A; Viana, A.R.L. Comunicação organizacional no espaço digital: o papel das Relações Públicas. Temática (João Pessoa. Online), v. 11, p. 125-137, 2015. Disponível em: $<$ http://periodicos.ufpb.br/index.php/tematica/article/viewFile/26519/14218>. Acesso em: 04 ago. 2017.

MAINIERI DE OLIVEIRA, T. (Re) pensando a comunicação organizacional na era digital. Revista FAMECOS (Impresso), $\quad$ v. $18, \quad$ p. $\quad 529-541, \quad 2011 . \quad$ Disponível <http://revistaseletronicas.pucrs.br/ojs/index.php/revistafamecos/article/view/9473>. Acesso em: 04 ago. 2017.

MARTINS, T. Estudo mundial levanta os dados da internet no Brasil e no mundo, descubra as principais redes sociais e comportamento de compras online dos usuários. Portal Marketing Sem Gravata. Abril, 2017. Disponível em: $\quad<$ http://marketingsemgravata.com.br/site/2017/04/17/dados-da-internet-2017-brasil-redessociais/>. Acesso em: 04 ago. 2017.

MONTEIRO, D. AZARITE, R. Monitoramento e métrica de redes sociais: do estágio ao CEO. São Paulo: DVS Editora, 2012. Xxx p. ISBN: 978-85-88329-01-2.

NASCIMENTO, L. L. Setor Público nas Redes Sociais Digitais: um estudo com comunicadores. In: ABRAPCORP 2013 - Teorias e Métodos de Pesquisa em Comunicação Organizacional e Relações Públicas: entre a tradição e a inovação, 2013, Brasília. ABRAPCORP 2013 - Teorias e Métodos de Pesquisa em Comunicação Organizacional e Relações Públicas: entre a tradição e a inovação. Porto Alegre: EDIPUCRS, 2013. $1949-967 . \quad$ Disponível em: $<$ https://www.alice.cnptia.embrapa.br/alice/bitstream/doc/990431/1/Setorpubliconasredessociaisdigitaisumestud 
ocomcomunicadores.pdf>. Acesso em: 04 ago. 2017.

OLIVEIRA, M. Monitoramento de mídias sociais. Material de aula. In: Laboratório de Social Media, Três Pontos, 2015.

RIBEIRO, M.E. Estratégias de Comunicação Organizacional Digital: O Estudo de Caso da EMBRAPA. 2014. 260f. Dissertação (Mestrado em Comunicação Social) - Faculdade de Comunicação, Universidade Metodista de São Paulo, São Paulo. Disponível em: $<$ http://tede.metodista.br/jspui/bitstream/tede/686/1/MariaRibeiro2.pdf >. Acesso em: 04 ago. 2017.

ROCHA, M. C. Mídias Sociais Digitais como fontes para a Gestão Estratégica da Informação no Setor Público: estudo de caso na BHTRANS - Empresa de transportes e trânsito de Belo Horizonte. 2014. Trabalho de Conclusão de Curso (Curso de Especialização em Gestão Estratégica da Informação) - UFMG- Escola de Ciência da Informação Programa de Pós-Graduação em Ciência da Informação, Belo Horizonte. Disponível em: $<\mathrm{http}$ //docplayer.com.br/18493012-Universidade-federal-de-minas-gerais-escola-de-ciencia-da-informacaonucleo-de-informacao-tecnologica-e-gerencial.html> Acesso em: 19 ju. 2017

ROCK CONTENT. Social Media Trends 2017. Disponível em: <http://pesquisas.rockcontent.com/redessociais/>. Acesso em: 04 ago. 2017.

SANTOS, G.H.C. O uso das mídias sociais no poder público: análise do perfil "Senado Federal" no Facebook. 2016. 148f. Dissertação (Mestrado em Administração Pública) - Escola de Governo Professor Paulo Neves de Carvalho, Fundação João Pinheiro, Minas Gerais. Disponível em: <http://tede.fjp.mg.gov.br/handle/tede/358>. Acesso em: 04 ago. 2017.

SANTOS, J.; HARMATA, F. Análise de Caso da Prefeitura de Curitiba - A relação entre humor e serviço público na comunicação em redes sociais. Intercom - Sociedade Brasileira de Estudos Interdisciplinares da Comunicação. XVII Congresso de Ciências da Comunicação na Região Sudeste. Bauru - São Paulo, 2013. Disponível em: <http://www.wegov.net.br/wp-content/uploads/2015/03/Artigo-An\%C3\%A1lise-de-Caso-daPrefs.pdf $>$. Acesso em: 04 ago. 2017.

SEEKR. Monitoramento de mídias sociais é base para estudo sobre saneamento básico em SP. Disponível em: <https://blog.seekr.com.br/monitoramento-midias-sociais-base-estudo-saneamento-basico-sp/>. Acesso em: 04 ago. 2017. 